This item was submitted to Loughborough's Research Repository by the author.

Items in Figshare are protected by copyright, with all rights reserved, unless otherwise indicated.

\title{
Government involvement in high performance sport: an Australian national sporting organisation perspective
}

\section{PLEASE CITE THE PUBLISHED VERSION}

http://dx.doi.org/10.1080/19406940.2016.1220404

\section{PUBLISHER}

(C) Informa UK Limited, trading as Taylor \& Francis Group

\section{VERSION}

AM (Accepted Manuscript)

\section{PUBLISHER STATEMENT}

This work is made available according to the conditions of the Creative Commons Attribution-NonCommercialNoDerivatives 4.0 International (CC BY-NC-ND 4.0) licence. Full details of this licence are available at: https://creativecommons.org/licenses/by-nc-nd/4.0/

\section{LICENCE}

CC BY-NC-ND 4.0

\section{REPOSITORY RECORD}

Gowthorp, Lisa, Kristine Toohey, and James Skinner. 2019. "Government Involvement in High Performance Sport: An Australian National Sporting Organisation Perspective”. figshare. https://hdl.handle.net/2134/22381. 
RESEARCH ARTICLE

Title: Government Involvement in High Performance Sport: A National Sporting Organisation Perspective.

Journal: International Journal of Sport Policy and Politics

Dr Lisa Gowthorp, Sport Management

Bond Institute of Health and Sport

Bond University, Gold Coast, QLD Australia

Email: lgowthor@bond.edu.au

Phone: +61 755954486

Professor Kristine Toohey,

Department of Tourism, Sport and Hotel Management

Griffith Business School

Griffith University, Gold Coast QLD, Australia

Professor James Skinner,

Director of Institute for Sport Business

Loughborough University, London, UK 


\begin{abstract}
The purpose of this paper is to examine the relationship between the Australian Federal Government (through the Australian Sports Commission) and Summer Olympic National Sporting Organisations (NSOs) to determine the effect the relationship has on Olympic performance outcomes. Five Olympic NSOs were examined: Athletics Australia, Cycling Australia, Rowing Australia, Swimming Australia and Yachting Australia. All five NSOs represent sports in which Australia has consistently achieved strong results at previous Olympic Games. Furthermore, these NSOs receive significant funding from the Australian Sports Commission (ASC) and, as such, are expected to achieve success at the Olympic Games. The ASC-NSO relationship was examined through an agency theory framework whereby the 'contracts' between the ASC (principal) and the NSOs (agents) were investigated through a survey, interviews and document analysis to identify potential management issues that may affect Olympic performance outcomes, such as agent or principal opportunism. The findings identified a lack of a unified and collaborative high performance sport system in Australia, with the findings emphasising concerns over the ASC's management of NSO programs. While the ASC staff identified their organisation as the leader of high performance sport in Australia, the study's NSO participants did not believe that the ASC had the capacity, capability and knowledge to fulfil this role.
\end{abstract}

Keywords: Australian Federal Government, Olympic Games, NSOs, Agency Theory 


\section{Introduction}

In Australia, National Sporting Organisations (NSOs) are responsible for managing their sport, from recreational participation through to elite performance. At the elite level, the NSOs receive significant funding from the Australian Federal Government to achieve international sport success (Shilbury and Kellett, 2011), especially success at the Olympic Games (Toohey, 2008). The Australian Federal Government, through the Australian Sports Commission (ASC), is generally the primary funding agent to the nation's NSOs, and it has an obligation to protect its funding through carefully monitoring and evaluating NSOs’ operations and performances. Additionally, the Australian Institute of Sport (AIS), a division of the ASC, plays a significant role in high performance sport through the management and administration of residential high performance sport scholarship programs. Therefore, the Federal Government in Australia plays a key role in the high performance management of Olympic NSOs (Green, 2007).

While generic factors (such as funding, coaching, talent identification and development) contributing to Olympic success are well researched (Oakley and Green, 2001, De Bosscher et al., 2006, Houlihan and Green, 2008), Arnold, Fletcher and Molyneux (2012) suggested that management practices and inter-organisational relationships have yet to be acknowledged as a contributing factor to successful Olympic performances, and thus have been under researched.

This study addresses that gap as it examines the perceptions of the management of ASC-NSO high performance relationships and the impact these relationships have on NSOs’ Olympic operations. This is significant as research suggests that Australia has maximised its international sporting success through the use of structured high performance sport systems that are now replicated throughout the world (Houlihan, 2013). Therefore, Australia must identify new ways to improve its international sporting 
success, rather than rely on current systems that appear to be no longer effective. One such strategy is to examine high performance sport management practices and interorganisational relationships as a way to improve Olympic performance (Arnold, Fletcher \& Molyneux (2012).

Issues within the ASC-NSOs’ relationship were identified through interviews with staff from the ASC, AIS and five selected NSOs (Athletics Australia, Cycling Australia, Rowing Australia, Swimming Australia, and Yachting Australia) whose athletes compete at the Summer Olympic Games. The data were analysed using a mixed methods approach through an agency theory framework.

The following section provides a brief background to the Australian high performance sport system, specifically Summer Olympic Games performances, and the key organisations being examined. Following this, the literature review outlines the research context, specifically literature relating to government involvement in high performance sport and agency theory. Next, the paper details the research methodology implemented in this study, followed by results and the discussion. The final section presents conclusions and outlines the contributions of the paper to the field of sport management knowledge and potential practical applications.

\section{Background}

Australian sport has gone through a series of major changes since the Australian Institute of Sport (AIS) was established in 1981 (Stewart et al., 2004). These changes have influenced the way the nation's high performance sport organisations have been managed. The AIS has played a significant role in shaping the structure of high performance sport in Australia by providing dedicated facilities to train and house elite Australian athletes as well as offering them comprehensive sports science and sports medicine services (Australian Sports Commission, 1998). 
Since the 1980s Australia has exceeded high public and government expectations in high performance sport results, with the Australian Olympic team achieving its best ever performance at the 2004 Athens Olympic Games, placing fourth on the Olympic medal table and winning 17 gold medals. However, since 2004, there has been growing concern by various stakeholders and academics surrounding the future direction of the Australian sport system and its ability to sustain the international sporting success that the Australian public and government have come to expect and demand (Ferguson, 2006, Australian Olympic Committee, 2009a, Crawford, 2009).

An independent review of the Australian sport system was conducted for the Federal Government in 2009 in order to assess the state of the Australia sport system. The review, 'The Future of Sport in Australia', was conducted by a panel led by David Crawford and is known colloquially as the Crawford Report (2009). The Crawford Report concluded that; “the current Australian sports system is very complex, inefficient and cumbersome” (p. 12) and Australia’s high performance sport system was described as "one of the greatest inefficiencies in delivering elite success on the world stage" (Crawford, 2009, p. 17).

Even the Federal Government agreed with the report's predictions of Australia's precarious position as a powerhouse in international sport and noted "we are not keeping pace with competing nations' efforts and we are rapidly losing our highly coveted competitive edge” (Australian Government, 2010). Academic literature has reached similar conclusions. For example, Sotiriadou (2008) believes the current high performance sport system will not result in sustainable sport success unless the right “strategies, actions, practices and relationships” (p. 855) are in place.

Results by the Australian Olympic Team at the London 2012 Olympic Games, where the team placed $10^{\text {th }}$ instead of the expected $6^{\text {th }}$ on the Olympic medal table, 
reinforced these concerns regarding the effectiveness of Australia’s high performance sport system, thus leading to the development of new high performance sport policy (Australia’s Winning Edge, 2012). In terms of accountability for this performance, blame was attributed not only to the team's management and high performance operations of the NSOs, but also to the Australian sport system and lack of government funding (Lane, 2012). As Federal funding supports high performance sport in Australia, it is understandable that the media and general public have a vested interest in the Olympic outcomes of the nation.

The ASC plays a key role in funding, developing, governing and educating NSOs to ensure there is a significant standard of management within these sport organisations. For example, the ASC requires that NSOs implement strategic and operational plans that measure NSO performance against clear KPIs to receive funding. In addition, the ASC demands that each NSO demonstrates an effective system of internal governance. In effect, the 'NSOs implement the strategies the Commission (ASC) formulates' (Sotiriadou, 2009, p. 848). This means that NSOs need to work closely with the ASC to ensure government policies are delivered, and currently it is through this relationship that decisions regarding funding are made.

\section{Literature Review}

\subsection{Research Context}

The current structure of the Australian sports system is a top-down complex hierarchy overseen by the Federal Government (Sotiriadou, 2009). In addition to funding NSOs, the Federal Government, through the ASC, provides leadership across the whole Australian sport system and as a result the ASC and "NSOs have developed a close working relationship, a partnership, to achieve sport goals” (Sotiriadou, 2009 p. 848). While the NSOs are responsible for the management of the elite athlete pathway within 
Australia for their respective sports (Shilbury and Kellett, 2011), it is the ASC that provides much of their funding and promotes the goal of increased international sport success (Australian Sports Commission, 2011a).

Despite or because of this close relationship, the Crawford Report (2009) suggested that the Australian sport system lacks national collaboration, coordination and leadership. The involvement of the AIS and the various State Institutes of Sport (SIS), plus the development of high performance sports clubs and sport academies around Australia, has added to the complexity of the system. Figure I below graphically displays the complexity of the Australian high performance sport system as it specifically relates to Olympic performance. The central organisation in Figure 1 is the NSO which is tasked with achieving successful Olympic performances. The NSO's relationship with the ASC is the focus of this paper. The two most influential organisations impacting NSO operations are the ASC and the AIS (Gowthorp, Toohey \& Skinner, 2014). This is due to the significant funding the ASC contributes to NSO operations and as a result, the ASC enforce strict accountability measures on the invested tax-payer money. Figure 1 also displays other organisations that have significant influence on NSO operations.

NSOs in Olympic sports are ranked by the ASC in tiers according to their potential to win Olympic medals (Australian Sports Commission, 2011a) and sports in the highest tier, with the most likelihood of medalling at the Olympic Games, are given the greatest financial support. The emphasis on winning Olympic medals is problematic for NSOs. Many nations, such as Australia, cannot continue to sustain their advantage in high performance sport, as there is a "distinct convergence in approaches to high 
performance sport management” (Houlihan, 2013, p. 27). Furthermore, Houlihan suggested an increasing number of nations have implemented a mimetic isomorphic approach to the areas of high performance sports science, technology, coaching and stateof the-art facilities. Therefore, creating a competitive advantage in the elite sport arena is becoming increasingly more challenging and expensive. Simply copying and adopting policies and practices from other nations which are successful, will not guarantee success. Instead, there is a growing awareness that the management and implementation of government and sport organisations' high performance policies contributes to the success of elite sport programs (De Bosscher et al., 2006).

Furthermore, how these organisations are led and managed will greatly contribute to the success of an organisation at the Olympic Games (Fletcher \& Arnold, 2011; Fletcher \& Wagstaff 2009). Arnold, Fletcher \& Molyneux (2012) concluded: If nations wish to maximise the likelihood of success at the Olympic Games, they must not only design and develop effective elite sport policies, they must also have the right personnel in place to lead and manage their Olympic programs, competently respond to and address issues, and create, optimise and maintain a high performance environment” (p. 318).

\subsection{Government involvement in high performance sport}

Government involvement in high performance sport is perceived to be beneficial to a nation's cultural, political and economic policy development (see Gordon, 1994, Bloomfield, 2003, Stewart et al., 2004, Houlihan, 2005, Houlihan and Green, 2008). Sam (2009) stated, "governments now have high expectations from their involvement with sport, including the prospects that it will generate economic growth, decrease health expenditures, promote social integration and develop national identity” (p. 500). Similarly, Grix \& Carmichael (2012) concluded that most advanced Western nations, 
such as Australia, rest on assumptions that elite sport success will lead to a "better image abroad, bolster national identity and stimulate domestic mass participation” (p. 86). Bergsgard, et al., (2007) suggested "government involvement in sport, has been justified in terms of its contribution to health benefits, military success, national pride, national unity, social peace and the reduction of crime” (p. 156) and is increasing for many nations (Houlihan, 2013). In Australia for instance: "So embedded are the institutional and administrative arrangements for elite sport development in Australia, that the Federal Government has been unable or unwilling to retrench from a position where it is highly supportive of elite sport policy” (Green and Collins, 2008 p. 242).

Negative media articles and public backlash following less than expected Australian sporting success attack government taxpayer money spent on high performance sport. Headlines in major papers such as: “Stop wasting taxpayers' money on sport funding”(Hull, 2014); “Money well spent? The Olympic dash for taxpayers cash” (Stoddard, 2012) and “It’s time to stop funding 'elite’ sports” (Barnes, 2014), suggest that the Federal Government, as well as NSOs, are under pressure to produce successful Olympic results.

The Federal Government not only funds Olympic NSOs, it is also heavily involved in their daily operations (Gowthorp, Toohey \& Skinner, 2014). Two consequences of the Australian Federal Government's involvement in high performance sport have been identified. First is a decline in the autonomy of NSOs, because NSOs have become dependent upon government funds and resources (Sotiriadou, 2009, Ferkins and Van Bottenburg, 2013). Second, the Federal Government is so entrenched in its quest for sustained international sport success, that it may be difficult for it to reduce its involvement in the administration of high performance sport and also difficult to reduce its ongoing investment in Olympic sport (Green, 2007; Houlihan, 2013). 
However, there is now pressure on the Australian Government to better manage their relationships with high performance sport organisations, due to the perceived national benefits high performance sport creates (Ferkins and Van Bottenburg, 2013). Moreover, in an attempt to improve their nation's international sport results, governments are attempting to prove their own legitimacy in the high performance sport environment by imposing systems and structures on NSOs to monitor and control high performance sport operations (Green \& Houlihan, 2006). Green and Houlihan (2006) suggested that this has resulted in a paradox as: "government has implemented programs designed (ostensibly) to empower and autotomize NSOs on the one hand while imposing centralised targets, directives and indeed sanctions on the other” (p. 49). For example, Australian NSOs must continue to meet the demands and targets imposed by the government if they are to continue to receive funding and resources from the ASC.

From an international perspective, Grix and Phillpots (2011) suggest that "government-led agendas frame sport policy, rather than the longer term interests and development of specific sports” (p. 8). As a result “NGBs [National Governing Bodies] are hidebound to their paymasters, the UK Government, and in effect this frames the manner in which sports are governed, the priorities they set and the decisions they make" (p. 9). Similarly, because of the ongoing resource dependency of Canadian NSOs on their Federal Government, they are also closely aligned with, and obligated to fulfil the requirements of their government (Kikulis, 2000). Therefore, findings of this research may assist UK and Canada in understanding relationships between their governments and NGBs.

Despite the increasing homogeneity of nations’ high performance operations, Houlihan (2013) suggested nations can still gain a unique edge in their approach to high performance sport management by increasing the support provided by the government to 
high performance sport. In the context of this paper, the ASC has aligned its invested \$120 million to sports with the greatest potential of achieving international sporting success, especially at the Olympic Games in Rio 2016 (Australian Sports Commission, 2015). Thus, Olympic medals remain important to the Australian public and for measuring the success of the ASC and of NSOs.

There is concern regarding the sustainability of the current increasing public investment in elite sport throughout the world, and Houlihan and Zheng (2013) suggest that the "upward competitive spiral is not sustainable, not only due to the escalating cost of winning a gold medal and maintaining a country's relative ranking but also due to the political risk of public disillusionment with excessive spending” (p. 352). All successful sporting nations have well developed elite sport systems and an influx of high performance funding (De Bosscher et al., 2006, Houlihan, 2013) and therefore, nations need to find alternative ways to gain a competitive advantage. Fletcher and Wagstaff (2009), suggested that; “the way individuals are led and managed will become an increasingly important factor in determining an NSO's success in Olympic competition” (p.433).

Statistics indicate that Olympic success is becoming harder to achieve as more nations are now competing in the Olympic Games and more nations are winning Olympic medals, especially gold (Houlihan, 2013). Figure II indicates the decline in Australia’s performance at the Olympic Games in relation to total/gold medals won.

Nevertheless, the Australian government has committed to the ongoing funding of high performance sport in Australia and maintains: 
High performance success is not only good for our athletes and our sense of national pride; it also contributes to other important government objectives in areas such as participation, economic development, health and education (Australian Sports Commission, 2012).

As noted above, the Australian Federal Government has committed to ongoing investment into high performance sport. However, the allocation of funding is targeted towards successful Olympic NSOs, thus placing increased importance on achieving international sporting success.

\subsection{International sporting success}

As successful results at an Olympic Games build national pride and unity within the country (Houlihan and Green, 2008), Australia’s performance at the Olympic Games is a key priority for the Australian Government and the nation as a whole (Australian Sports Commission, 2012b). Australia has consistently achieved success at the Olympic Games, however it is believed that the country's performance is on a downward trend and that the nation cannot maintain its current international sporting performances (Australian Olympic Committee, 2009c, Crawford, 2009, Halsey, 2009). While previously blame for the decline has been placed on Federal Government funding of high performance sport (Oakes, 2012), a recent explanation for the decline has been suggested by the AOC’s President, John Coates, who claimed it is management and high performance operations that are impacting performance, rather than a lack of funding (Lane, 2012).

Despite early success from the centralised AIS model implemented in 1981, declining international competition results, as indicated in Figure II, suggest changes need to be made if Australia is to maintain its top five position on the Olympic medal tally. Researchers have differing views on what needs to occur in order to achieve 
greater international sporting success with NSOs and the role of government, key areas of consideration (Green and Oakley, 2001, Crawford, 2009, Grix and Carmichael, 2012, Houlihan and Zheng, 2013, Arnold et al., 2015). Sam (2009) believed there is an increasing demand for NSOs to be "professionalised, modernised and commercialised" (p. 501) in order to achieve governments' high performance sport desired outcomes. Whereas, according to De Bosscher, Shilbury, Theeboom, Van Hoecke and De Knop (2011), policy makers need "to understand how their structures and processes enable or hinder those [performance] outcomes” (p. 136). Consequently, the relationship between the government and NSOs/NGBs is a topic worth investigating and has global relevance for any nation reliant upon government funding to support Olympic sport programs.

\subsection{Management and governance of high performance sport programs}

According to Ferkins and van Bottenburg (2013), there is pressure on government to better manage its relationships with high performance sport organisations, due to the perceived benefits high performance sport can create. They believed questions such as; “"how to steer?”, "how to increase efficiency?”, "how to improve accountability?” and "how to gain and maintain legitimacy?”' (p. 127), have become the focus for many governments trying to improve their international sport results.

The ASC has implemented various programs for NSOs to ensure they meet professional and commercial outcomes. Crawford (2009) discovered that there is a fragmented approach to how government manages, supports and communicates with NSOs. Recent literature has examined the role of the National Performance Director (NPD) in the management and leadership of their organisations (Sotiriadou, 2013, Arnold et al., 2015), yet only limited literature examines the management of the relationship between the government and the NSOs (Gowthorp, Toohey \& Skinner, 2014). 
According to Stoker (1998), governance should not be defined as the control of resources and spending by government, but rather, as the ability of the government to make decisions and enforce them without relying solely on its authority and power. $\mathrm{He}$ suggested that "governance recognises the capacity to get things done which does not rest on the power of government to command or use its authority” (p. 18). Further research suggests that sport organisations are very diverse and no two organisations are the same (Healy, 2012), suggesting there is no single model of NSO governance. Moreover, Healy suggested that issues of NSO governance are complicated, as standard business corporate governance assumptions generally do not apply to sport organisations. She concluded that governance paradigms for sport, such as those imposed by the ASC on NSOs, should take into consideration the unique features of sport organisations and apply governance models that are effective and improve outcomes rather 'than merely compelling sports to behave in a uniform manner' (p. 55). Nevertheless, the ASC demands NSO conformity in adhering to requirements for high performance funding as noted above.

This paper examines this ASC-NSO high performance relationship through an agency theory framework, in order to identify key issues and concerns of the relationship as perceived by ASC and NSO staff. The following section will briefly outline agency theory and its application within the context of non-profit sport organisations.

\subsection{Agency Theory}

Agency theory was first used in the studies of organisational economics (Mason and Slack, 2005), however it has since broadened its utility and is now utilised by various researchers in many other fields, such as organisational behaviour (Eisenhardt, 1989), sociology (Shapiro, 2005) and sport (Mason and Slack, 2005, Mason et al., 2006). Agency theory is useful in understanding a variety of organisational phenomena (Van 
Slyke, 2006) and, as such, is ideal for the "analysis of hierarchical relationships” (Moe, 1984 p. 758), such as the Australian sport system.

An agency relationship is defined as one; “whereby a party, the principal, tries to motivate another (or others), the agents, to act in a manner advantageous to the principal" (Mason \& Slack, 2005 p. 49). Agency theory seeks to understand the relationships that exist between principals and agents, whereby the services of the agent are acquired by the principal, which typically does not possess the time, skills or knowledge to perform the services itself (Mason \& Slack, 2005). Consequently, the principal may not be completely aware of the activities an agent undertakes while acting on their behalf. This knowledge gap between the principal and agent is termed information asymmetry (Mason et al., 2006) as the principal cannot "perfectly and costlessly” (p. 2) monitor the agent's action and information (Pratt and Zeckhauser, 1985). Thus, the premise of agency theory is the dependence of the principals on agents to achieve the principal's goals and outcomes and why this does or does not occur (Shapiro, 2005).

Classic agency theory assumes that agents may behave opportunistically or in self-interest when their interests are not aligned with those of the principal (Jensen and Meckling, 1976, Fama, 1980, Eisenhardt, 1989). Dial and Zardkoohi (1999) believe classic agency theory often portrays the agent as "devious, dishonest and opportunistic" (p. 2), whereas the principal is typically viewed as the "saint” (p. 2). Recently, agency theory literature has broadened its perspective and examined behaviour of both principal and agent. Shapiro (2005) suggested that the rationale for this extension is that the behaviour of the principal should also be examined because "agency problems on the agent side of the relationship are often mirrored on the principal side” (Shapiro, 2005 p. 268). 
Pratt and Zeckhauser (1985) believed that a principal's involvement in an agent’s daily operations may ‘inevitably reduce the efficiency’ (p. 28) of efforts to achieve the desired outcomes. According to Hendry (2005) principals in agency relationships can create problems due to their own limited competence. Principals may have limited competence to 'know what they want (or what they would in retrospect have wanted) from their agents' (p. 59).

Jensen and Meckling (1976) defined a principal-agent relationship as a contract whereby the principal requests the agent to perform services on their behalf. Similarly, Shapiro (2005) suggested agency relationships are contracts that incorporate "incentives, monitoring devices, bonding, and other forms of social control” (p. 266). Contracting problems may occur if the agent is not working in the best interest of the principal and also if the principal has few options in the selection of the agent (Eisenhardt, 1989).

Researchers have examined organisational behaviour and organisational relationships in sport organisations using agency theory. Mason, Thibault and Misener (2006) used an agency theory framework to assess the behaviour of selected International Olympic Committee (IOC) members. Their results suggested that the IOC (the principal) needed to introduce additional stakeholders into the management and control functions within the organisation to reduce the 106 members' (agents') opportunism. In another example, Mason and Slack (2003) utilised agency theory to examine the relationship between players and agents in the sport of professional hockey. Their research identified changes in the industry that resulted in better certification of agents and a more competitive agent market. Mason and Slack concluded that better systems to monitor and assess agents will produce a more effective and robust principal-agent relationship over time, resulting in reduced agent opportunism. They also suggested the application of agency theory was appropriate to understand sporting organisations and their governance. 
For this study, the NSOs are considered to be the agents and the ASC is the principal. Together they develop and implement a high performance plan that is the contract binding the relationship between the ASC and NSOs, in managing high performance sport. The ASC develops guidelines and assessment tools to monitor and evaluate NSOs’ performance annually and also implements monitoring mechanisms and incentives to guide NSOs' behaviour to achieve the government's desired high performance sport outcomes, in this case, athletes winning Olympic medals. While the desired outcome is similar for both the ASC and NSO, that is achieving Olympic medals, it is the process through which to achieve this outcome that is the cause of conflict between the ASC and NSO. According to Tasoluk, Yaprak and Calantone (2006), the principal and agent may agree on the goal, yet disagree on the means to achieve that goal. Thus, agency theory is an appropriate conceptual approach to examine the ASCNSO relationship to gain an understanding of the dominant role the ASC, as the principal, plays in this relationship.

\section{Methodology}

This exploratory study investigated how the ASC/AIS and selected Olympic NSO staff perceived the ASC-NSO relationship and how it impacted the NSOs' ability to deliver successful high performance programs, specifically in relation to performance at the London 2012 Olympic Games. The two research questions that underpinned the study are:

1. Are there perceived issues arising from the management of the ASC-NSO relationship and, if so, what are they?

2. How are these issues perceived to impact the management of NSOs' Olympic operations? 
The research incorporated a multiple case study design. This design approach was chosen as case study research is examined in a real-life context that allows investigation of a particular situation, event, program or phenomenon (Edwards and Skinner, 2009) and is designed to examine significant factors that occur within a set context, rather than examining these factors in isolation (Yin, 2003). While five case organisations were examined, a pilot study was conducted with another NSO to test the research tool, ensure reliability and that the data collected would address the research topic.

\subsection{Case selection}

Five Australian Olympic NSOs were selected as case studies. The five case NSOs chosen were: Athletics Australia; Cycling Australia; Rowing Australia; Swimming Australia; and Yachting Australia. The case NSOs were chosen based on the following criteria: their funding allocations from the ASC; they are a multi-discipline/event sports (that is, sports that have the potential to win many medals at the Olympic Games); and they were expected to medal at the 2012 London Olympic Games (Australian Olympic Committee, 2009b). Additionally, these organisations were the NSOs which received the greatest amount of funding from the ASC in the 2010/2011 financial year (Australian Sports Commission, 2011b). For instance in 2011, Australian Swimming received just over \$10 million dollars from the ASC for its high performance sport operations. Before the London 2012 Olympic Games, the five case NSOs’ athletes had won the most medals at the Olympic Games for Australia, with swimmers winning 178 medals; athletics 71 medals; cyclists 40 medals; rowers 37 medals; and sailors 23 medals (Australian Olympic Committee, 2012). Moreover, at the 2008 Beijing Olympic Games, athletes from the five selected NSOs won 67 percent (31/46 medals) of the total Olympic medal haul by Australian athletes (Australian Olympic Committee, 2010). Results in London 
2012 further cemented the selection of these five selected NSOs as combined they won 80 percent (28/35) of the total Australian medal haul.

\subsection{Data Collection}

A variety of data collection methods was implemented as, according to Yin (2009), the use of multiple sources of evidence ensures rigour in case study research. The research had three distinct data collection phases that utilised different methods of data collection. The first phase of the research design collected and analysed key documents that identified issues surrounding the relationship between the ASC and Olympic NSOs. Documents included annual reports, high performance plans, strategic documents and newspaper articles. The documents were read and examined for information that would assist in answering the research questions and shed light on the relationship between the ASC and NSOs. Data collected during this phase shaped the research questions and identified a priori codes.

The second phase of the study was a self-administered questionnaire for ASC and NSO high performance staff members (including AIS staff members) that sought their understanding of the issues relating to the relationship between the ASC and NSO. Participants completed the questionnaires anonymously online. The questionnaires were produced and managed through a survey tool, Qualtrics. The data obtained in the second phase provided the content in order to develop the semi-structured interview template for the final phase of the research.

The final phase of the research was to conduct semi-structured in-depth interviews with selected NSOs and the ASC (including the AIS) high performance staff members. The use of semi-structured interviews specifically sought information relating to the perceived strengths and weaknesses of the current relationship between the ASC and NSOs. In total, 32 semi-structured interviews were conducted with staff from the case 
NSOs, the ASC and the AIS. Table 1 below indicates the position held by all interviewees and demonstrates the information rich potential of the interview participants. Sample selection was dictated by the roles within each case organisation, as only a small number of participants could provide in-depth insight into the ASC-NSO relationship. To ensure confidentiality and protect the respondents’ personal information, a further breakdown of positions from within each organisation is not included.

Insert Table I here

Despite the interviews being guided by an interview schedule, the interviews followed the direction of conversation taken by each respondent ensuring a semistructured approach was maintained. All participants demonstrated a willingness to participate and were open and candid in their responses, with the average interview time approximately 50 minutes. The interviews were spaced to provide the researcher the opportunity to transcribe and analyse the interview after each visit to ensure the data collected was addressing the research problem and to determine when data saturation occurred.

For analysis, each interviewee was identified by a respondent number linked to their organisation. For example, the ASC respondents were identified as ASC1 through to ASC12. In order to preserve the confidentiality of each NSO, as required by the case organisations in the study's ethics approval, the case NSOs were assigned a letter rather than being identified by sport to de-identify the respondents within each NSO. For example, NSOa2 would indicate the NSO case study organisation (a) and the respondent number two from that NSO.

\subsection{Data Analysis}


The interview transcripts were coded in order to identify and cluster all data segments into themes or concepts that related to the research question (Miles and Huberman, 1984). Through coding, the raw data were sorted into conceptual categories, creating themes that demonstrated relationships between the various concepts. The method of analysis for this research was a combination of thematic analysis through a data-driven inductive process (Boyatzis, 1998) and a deductive approach using an a priori code template (Crabtree and Miller, 1992).

Three a priori codes were developed from the initial content analysis phase. These three a prior codes, (Olympic performance; Communication; Roles and responsibilities), were linked directly to the research problem and provided categories to classify the interview data. The coding process was undertaken manually to allow the researcher to gain a feel for the data. The first stage of data analysis involved applying the template of codes to the raw data, with the aim of identifying meaningful units of texts within each of the a priori codes. Where data did not fit into the a priori codes they were placed into a code of 'Other' to be analysed for relevance to the research questions at a later date.

The researcher read and re-read the meaningful units of text within each a priori code in order to identify inductive codes. The list of inductive codes was then analysed to identify concepts that connected the inductive codes within each a priori code. This process involved grouping and refining the inductive codes into smaller distinct concepts that were still reflective of the data (Gall et al., 2007). This process also provided the researcher with an opportunity to look for patterns and explanations in the data. The final stage of the data analysis combined concepts into a thematic schema that was used to display the overall findings of the research. Creswell (2003) states 'these themes are the ones that appear as major findings in qualitative studies’ (p. 5). By identifying relationships between themes within the a priori codes, a 'story-line' emerged for 
reporting results. Table II below displays the themes that emerged under each a priori code.

Insert Table II here

\subsection{Limitations of the Research}

The case study for this research was completed at a specific time, prior to the London 2012 Olympic Games, and gathered views, opinions and beliefs from ASC, NSO and AIS respondents, which may change. The research is cross-sectional and therefore no follow-up interviews were conducted to assess whether opinions and attitudes were consistent over time. The data were gathered at a time of change and restructure within the ASC and AIS, potentially influencing the respondents' opinions. In addition, the data collected was from Australian NSOs and government agencies only, however findings may be relevant to other nations operating under similar government led Olympic sport systems, such as the UK and Canada.

\section{Results and Discussion}

The review of literature and the analysis of interview data highlighted issues in the management of the ASC-NSO relationship and the impact on NSOs' Olympic preparations caused by government involvement in high performance sport operations. Findings from this research have identified issues within the ASC-NSO relationship that have impacted the NSOs’ ability to operate their Olympic programs effectively. The results and discussion that follows are presented under the two research questions identified earlier.

5.1 Are there perceived issues arising from the management of the ASC-NSO relationship and, if so, what are they? 
The findings revealed various issues identified by respondents that are a result of the working relationship between the ASC and NSOs. The identified issues highlighted concerns regarding; communication, especially around government bureaucratic requirements; a lack of understanding of each organisations roles and responsibilities; and finally, limited clarity in the roles and responsibilities of the ASC and the AIS. Further explanation of the issues is outlined in the following section.

\section{Lack of understanding of high performance operations}

More than half of all NSO respondents believed ASC staff lacked a solid understanding of NSOs' operations and this shortcoming hindered the ASC's ability to help NSOs achieve their Olympic objectives. This finding aligns with the agency theory notion of information asymmetry (Eisenhardt, 1989). Respondent NSOd2 stated that; "There is a lack of understanding within the [Australian] Sports Commission about how NSOs have to operate.” Respondent NSOb2 stated that: “They're [ASC] focussing on excellence but actually to get excellence you need to have it as a focus priority. Look at all the other sports, all of our national team sports are not about excellence, they're about equality”.

Respondent ASC10 suggested how the ASC could add value to the ASC-NSO relationship to improve Olympic performance results: "If we want a different result, we've got to be prepared to do things differently and they've got to be at the strategy level and they've got to be at the structural level.” This view is aligned with findings of Arnold et al., (2012), who suggested that Australia has maximised its Olympic performance through the use of quality coaching, sports science, sports medicine and competitive daily training environments, but the nation has yet to maximise its performance through the analysis and improvement of the relationships in high performance sport. 
The findings of this research suggest that the current Australian high performance sport system relies too heavily on government involvement and this hinders NSO's daily operation, specifically its Olympic preparations. While it was perceived that the ASC staff attempt to assist NSOs, respondents thought that the ASC staff did not have the ability, time or focus to do so effectively. For example, Respondent AIS5 commented: "I think we [ASC] are trying to be all things to all people and I think when we have limited resources we don’t have the stretch. So our reach is wide but not deep.” In addition, NSO respondents stated their frustration at the lack of support they receive from the ASC in achieving the high performance plan objectives, as set out in the ASC-NSO contract. NSO1 explained: We've reformed ourselves to the level where we're trying to give our [high performance] plans primacy, and you [ASC] are unable to reform yourself within the context of that plan being the primary driver of performance. There are some anomalies there.”

Delays in decision making and the hesitation of the ASC to implement new high performance sport strategies and support NSO high performance sport initiatives were seen to negatively impact on NSOs Olympic operations. According to Sam (2009), the ASC's lack of technical knowledge of high performance sport operations may result in delayed or incorrect decisions. Respondent ASC10 acknowledged: "the reality is the delivery of high performance sport is utterly different to the delivery of community participation sport” thus acknowledging the complexity of the high performance environment and realising that not all ASC staff understands such complex environments.

\section{Communication}

More than a half of NSO respondents believed the frequency of requests for information from the ASC impacted on their normal daily high performance operations 
and that the ASC gave little consideration to these operational effects, especially when information was demanded immediately. As a result, important NSO high performance tasks and projects had to be put aside. Often the ASC gave little or no explanation of why the task needed to be completed urgently or even its relevance. Respondent NSOa1 suggested:

Communication could be improved by considering the tight implications of tight timeframes - i.e. distraction from other important NSO tasks, insufficient turnaround time and therefore consideration of response by NSO, including the inability of NSO to properly brief key stakeholders like the board, council etc. While all respondents understood the government's influence was "part and parcel of the politics of the commission [ASC]” (NSOe2), nevertheless, NSO respondents believed “they [ASC] need to contain it and be more efficient around it, so that it doesn't impact on sports” (NSOe2).

\section{Government bureaucratic requirements}

The ASC's failure to make decisions, or delays in the decision making process were other concerns regarding ASC-NSO communication. The majority (90\%) of NSO respondents believed the bureaucracy of the ASC contributes to the slow ASC decisionmaking processes and that this negatively affects NSO Olympic operations. One NSO respondent stated that 'ASC corporate inertia and delayed decision-making is debilitating for sport' (NSOa1). A third of NSO respondents reported there are often too many people involved in the decision-making process at the ASC (NSOe1, NSOa1, NSOb1, NSOb2). This, they said, further slows down the process and delays decision-making for the NSO. Respondent NSOe2 claimed that 'the ASC will just paddle the usual political 'sit on the fence' and wait for it all to resolve itself to a certain degree and there's an enormous 
amount of time wasted around the big issues, because they don't feel their mantra or the ethos of what's going on is clear'.

While the majority (72\%) of NSO staff acknowledged the requirement of the ASC to protect its investment and resources allocated to the NSOs, they suggested more autonomy should be given to NSO high performance operations. NSO respondents questioned their level of organisational autonomy with NSOa1 stating: "I even heard a commission [ASC] person say "if we think that a sport should concentrate on xyz, then that’s what they should do because it’s our money” and I said “that’s ridiculous!” Similarly, respondent AIS4 stated: “I mean we’ve always said ‘sport runs sport’ but really we say 'sport runs sport unless they disagree with us'” (AIS4). Therefore, the ASC's management of the ASC-NSO high performance relationship was seen by NSO respondents as controlling, with the ASC directing and influencing NSO operational strategy, primarily as a result of its direct investment into NSO high performance operations and in the attempt to achieve successful sporting outcomes.

\section{Roles and Responsibilities}

The perceived roles and responsibilities of staff within the high performance units of the ASC, AIS and NSOs contributed significantly to the issues associated with the ASC-NSO relationship. Concerns by all respondents were related to organisational capability and capacity, and the ability of staff to complete the tasks associated with their roles. As such, conflicting results emerged, where both the principal and agent believed the other was not capable of completing tasks required of them.

When asked to define and identify the roles and responsibilities of the ASC and the AIS, all respondents believed there was confusion about the goals, purpose and aims of the ASC. Respondent NSOa1 stated: “I don’t think there is a common understanding about what the purpose of that place is over there, be it the AIS or the Sports 
Commission [ASC].” In addition, respondent NSOd1 stated, “I don’t think it’s clear about leadership role versus delivery. The challenge for the ASC and AIS is actually being very clear about who’s doing what.”

Furthermore, respondent NSOe2 believed, “there can’t be clarity because they [ASC] are changing too many times and reviewing every six months. What the ASC and AIS struggle with will be how they are going to actually help NSOs achieve their goals.” Another NSO respondent commented that; "I think they [ASC] are probably struggling to identify what their role is, and how they can be most effective” (NSOc2). Tasoluk, Yaprak and Calantone (2006) suggest that it is the role of the principal to increase its credibility with the agent and convince the agent it is competent.

Criticism from within the sport industry and made public in the Crawford Report (2009), indicated that neither the NSO nor the ASC staff, have effectively built the capacity and capability of the NSOs during their 20 year relationship. According to the Crawford Report: "It would seem that something is seriously wrong if sports that have received major funding for almost two decades have not yet acquired the expertise to manage their own sports” (p.20). Respondent AIS5 reinforced the long duration of the issue stating; “you know the analogy, for a long time we’ve handed out fish and we haven't taught the NSOs to fish.” The ASC respondents believed their role, when working with the NSOs, was to ensure NSOs moved towards professionalization by incorporating good governance practices. Furthermore, ASC respondents believed they had the required skill and expertise to assist NSOs to develop organisational capacity and capability.

However, NSO respondents believed the ASC implemented a 'one size fits all' approach to its management of Olympic NSOs regardless of the fact that sport organisations are very diverse and no two organisations are the same. This result echoes 
the findings of Healy (2012) who concluded that governance paradigms for sport, such as those imposed by the ASC on NSOs, should take into consideration the unique features of sport organisations rather "than merely compelling sports to behave in a uniform manner” (p. 55). The finding of this study suggested that a uniformed approach to the management of NSOs by the ASC had impacted NSO Olympic operations. Therefore, in order to improve high performance outcomes, elite sport policy makers, such as the ASC need to understand how their policies and processes may hinder performance outcomes (De Bosscher et al., 2011).

Facilitating high performance relationships involves a degree of trust (ASC1, ASC2) and due to the nature of an agency relationship, where principal or agent opportunism is expected, trust between the ASC and NSOs was not evident. One NSO respondent, admitted, "there is only a limited amount of transparency and openness you can have because you know it will be used against you" (NSOa1). There is a conflict of interest as the ASC's role is to reward as well as sanction NSO behaviour, and yet the ASC is directing NSO behaviour. Respondent ASC2 surmised: "How can you be an auditor and be an advisor, because it's a conflict. We try to be a critical friend and then we are going to assess the NSO. So it's a bit of a conflict in role I think.” As a result, NSO respondents admitted they were hesitant to confide in ASC staff if there were problems in their Olympic preparations or daily operations.

In summary, NSO respondents perceived their relationship with the ASC as fraught with issues, specifically linked to the bureaucratic nature of the ASC, whereby Federal Government agendas and mandates undertaken by the ASC are perceived to impact NSO Olympic operations.

\subsection{How are these issues perceived to impact the management of Olympic operations?}


Performance at the Olympic Games is a heavily weighted KPI for all Australian Olympic NSOs. As reported by Houlihan and Green (2008), the Olympic Games are an important event for Australia, with Australia's success believed to unify the nation and provide social, political and economic benefits. Because of its funding of the case NSOs, Olympic medals (especially gold) are expected by the ASC (Australian Sports Commission, 2011c). In agency terms, the ASC's desired outcome is to achieve Olympic success and it contracts the NSOs to achieve this outcome on its behalf.

One respondent argued that the current ASC-NSO relationship had affected the NSO’s preparations for the London 2012 Olympic Games, and prior to the London Games this respondent stated:

The lack of understanding and delayed decision-making processes impact on a sport's ability to plan for and implement key initiatives that it knows will make a positive impact on performance. Until recently, this has been a major issue and will have an impact on London performance (QNSOr12).

Despite its financial support, the involvement of the Federal Government in the NSOs' high performance sport operations was highlighted in the findings as a hindrance to NSOs' Olympic preparations. While NSOs acknowledged the requirement of the ASC to protect its investment and the resources allocated to the NSOs, respondents suggested more autonomy should be given to NSOs to carry out their operations. In addition, NSO respondents believed that the ASC should trust that the NSOs, as agents, have the expertise needed to achieve the desired outcomes of both organisations.

Respondents suggested the ASC should not be involved in the dynamic high performance sport environment due to the bureaucracy of the organisation and the political influence on ASC priorities. ASC respondents acknowledged the ASC's 
limitations due to political influences: 'We are a bureaucratic organisation and decisions we have to make in this organisation by their very nature take a long time' (ASC1).

The criticism of the ASC by the NSO respondents stems from the ASC's dual role in managing elite sport programs and programs related to mass participation sport. Respondent ASC10 acknowledged that 'the delivery of high performance sport is utterly different to the delivery of community participation sport’. Green and Houlihan (2006) concluded that a failure of the ASC's governance of sport was that it tried to support the twin objectives of promoting mass participation and elite sport. Instead, NSO respondents indicated strong support for the AIS and its more experienced high performance staff to take a greater leadership role in the governance and management of NSOs' high performance operations. This was because AIS staff do not contribute to the areas of sport participation and their expertise is in high performance sport.

\section{Conclusion}

In conclusion, this study found that the relationship between the ASC and the five case NSOs is perceived to have had a negative effect on NSO's high performance operations, which may have had an impact on the performances at the 2012 London Olympic Games. How Olympic sports are managed is becoming increasingly important in the relentless competition to achieve Olympic success (Green and Oakley, 2001, De Bosscher et al., 2006, Houlihan and Green, 2008, Fletcher and Arnold, 2011, Arnold et al., 2012). The relationship between the ASC and NSOs will continue to be crucial for Australia's high performance sport system, as long as the Federal Government continues to invest in NSO high performance operations. Therefore, the outcomes of this research can assist in the development of more strategic methods to manage the ASC and Olympic NSOs' relationships. Furthermore, findings from this research may provide lessons learned to other nations with government led Olympic programs, while also highlighting the 
importance of the relationship between the government and its national sporting agencies.

\subsection{Practical Outcomes}

This paper demonstrated that the management of the ASC-NSO relationship was perceived to have a negative impact on the NSO's ability to deliver high performance programs. ASC staff were perceived to have a lack of legitimacy within the high performance sport environment that resulted in the potential for agent opportunism. Managing high performance sport is complex, with respondent AIS6 stating; "High performance sport is becoming a discipline in its own right and encompassing a knowledge of high performance sport, sport science and sport medicine, coaching and coach development, research, logistics, finance and so on.” Moreover, NSOs staff want to work with "high level talented people" (NSOd1) who can assist NSO staff to develop high performance capability and capacity within their own sport.

Involving NSOs in the ASC’s policy making and assessment processes will assist in providing NSOs with a better understanding of the strategic direction implemented by the ASC. This finding supported the agency theory premise that suggested the inclusion of the agent in the decision making process is advantageous to the agency relationship (Shapiro, 2005). If an agent is involved in the development of the reporting, planning and evaluation processes, agency theory postulates agents are more likely to achieve the desired outcomes of the principal (Pratt and Zeckhauser, 1985).

\subsection{Theoretical implications}

\section{Agency theory}

Various external stakeholders have a significant influence over the ASC-NSO relationship, as identified earlier in Figure I, and the influence of these stakeholders may impact the desired outcome of an agency relationship. In this case, the NSOs had 
difficulty meeting the demands imposed upon them by the ASC, as many NSOs were also attempting to meet the requirements of their other external stakeholders. NSOs were limited in their capacity and capability to successfully complete all obligations required of them by the various stakeholders and therefore, NSOs may not be deliberately acting out of self-interest within their ASC relationship, as presumed within agency theory.

Therefore, the findings of this research support agency theorists who have advanced the understanding of agency theory relationships by investigating the social conditions in which the principal-agent relationship exists (White, 2008). The relationship does not operate in isolation and external factors that impact the agent and the principal should not be overlooked when examining a principal-agent relationship, as these external factors may inhibit the agent from achieving the principal's desired outcomes.

Agency theory suggests that by identifying appropriate rewards and incentives for non-profit organisations, the principal will have greater control over agent behaviour (Mason \& Slack, 2005). However, monetary incentives, especially incentives in the form of individual payments to NSO employees, may not be not feasible in non-profit, taxpayer funded organisations. Thus, non-monetary incentives can be effective within nonprofit agency relationships, such as the ASC-NSO relationship. For example, the respondents believed a collaborative ASC-NSO relationship in which the NSOs have greater involvement in decision-making, planning, goal setting and performance evaluations would be an incentive for NSOs to work more effectively to achieve the ASC's objectives.

\section{Sport Management}

A perceived lack of coordination and collaboration and the lack of a national leader in Australia's high performance sport system has created issues that have been 
mounting over many years (Crawford, 2009). At the London 2012 Olympic Games, Australia again slipped down the Olympic medal table with performances meeting neither the ASC's or AOC's desired levels. This research suggested that more money is not the answer. Instead, one solution is that the ASC focus on developing a collaborative and effective relationship with the NSOs. Clearly there is a need for the ASC and the Olympic NSOs to better manage their inter-organisational relationships and organisational capability.

The contribution of this research to sport management and the governance of sport extends findings by Fletcher and Arnold (2009) who concluded that: 'in order to attain and sustain successful [international sporting] outcomes, initiatives need to be inspirationally led, effectively managed and competently executed' (p. 427). The findings of this research demonstrated that the ASC's high performance sport initiatives were sometimes poorly executed and ineffectively managed, and as a result they impacted NSO Olympic operations.

In summary, this thesis makes an important contribution to the sport management and sport governance knowledge base by addressing an identified gap in the literature. The current literature associated with sport management and sport governance generally examines organisational governance and sport management practices in non-elite sporting organisations. Very few studies have examined the management of the relationship between high performance sport organisations and government, and very few have been examined from an operational perspective. The findings can also be applied in a global context, whereby those nations operating Olympic sport programs with the involvement of government, are able to learn from Australia, and implement strategies to improve the government-Olympic NGB relationship.

6.3 Government's role in managing Olympic NSOs 
In the context of research in high performance sport, the examination of organisational relationships and their management have been overwhelmingly ignored, especially in relation to government involvement in high performance sport policy. This paper provided an understanding of how the ASC impacts NSOs' high performance programs and the effect government intervention has had on Olympic performance preparations.

The ASC/AIS has an opportunity to build collaborative and effective relationships with Olympic NSOs by assisting individual NSOs to build their capability to achieve Olympic success. While government funding is essential for NSO survival in Australia, developing stronger, more effective working relationships between government sport organisations and NSOs can provide an opportunity to improve international sporting success, and allow the government to achieve the expected return on their investment. As highlighted in research by Arnold et al. (2012), nations must develop effective sport policies and ensure the right staff can lead and manage Olympic sport programs within the high performance sport environment.

\subsection{Future Research}

The ASC and AIS made significant changes to their structure and functions, following disappointing results in London 2012. ‘Australia’s Winning Edge’, released by the ASC in December 2012, is the new high performance plan for the ASC and AIS and clearly states the Federal Government's international medal performance criteria and identifies the AIS as the most appropriate organisation to drive high performance sport in Australia (Australian Sports Commission, 2012). Extending the findings of this paper could be used to investigate the effectiveness of 'Australia’s Winning Edge’. Future research could interview the same five case NSOs examined in this paper to determine what effect, if any, the new policy with its change of governance and management 
systems has had on the case NSOs. The research could identify if any issues still exist in the new AIS-NSO relationship and also assess the perceptions of the ASC/AISs' involvement in the new structure.

As the findings from this research may be beneficial to other nations with significant government involvement in Olympic sport programs, an additional research project could examine these other nations to determine how they manage their government-NGB relationship. Nations such as the UK and Canada also rely on government funding and resources to run their high performance sport programs. Therefore, comparing how these nations manage the government-NSO relationships may be advantageous in order to compare international sport policies and high performance sport relationships. 


\section{References}

Arnold, Fletcher, D. \& Anderson, R., 2015. Leadership and mangement in elite sport: Factors percieved to influence performance. International Journal of Sports Science \& Coaching, 10, 285-304.

Arnold, R., Flectcher, D. \& Molyneux, L., 2012. Perofrmance leadership and management in elite sport: recommendations, advice and suggestions from national performance directors. European Sport Management, 12, 317-336.

Australian Government, 2010. Australian Sport - the pathway to success. Commonwealth of Australia 2010.

Australian Olympic Committee, 2009a. The AOCs response to the Crawford report. Australian Olympic Committee.

Australian Olympic Committee, 2009b. National high performance plan for olympic and paralympic sports in Australia. Sydney: Australian Olympic Committee.

Australian Olympic Committee, 2009c. National high performance plan for olympic and paralympic sports in Australia [online]. Australian Olympic Committee. Available from: www.corporate.olympics.com.au/files/87/AOC_High_Perf_Plan_2009.pdf [Accessed 14 January 2009].

Australian Olympic Committee, 2010. Games at a glance [online]. Available from: www.olympics.com.au/index.cfm?p=22 [Accessed 22 February 2010].

Australian Olympic Committee, 2012. Games at a glance [online]. Available from: www.olympics.com.au/index.cfm?p=22 [Accessed 16 August 2012].

Australian Sports Commission, 1998. Excellence - The Australian Institute of Sport Canberra: The Australian Sport Commission.

Australian Sports Commission, 2011a. Annual National Assessment. ASC handout.

Australian Sports Commission, 2011b. Annual Report 2010/2011.

Australian Sports Commission, 2011c. Investing in Green and Gold - A National High Performance Strategy. Insider Document.

Australian Sports Commission, 2012. Australia's Winning Edge. Canberra: The Australian Sports Commission.

Barnes, T. 2014. Its time to stop funding elite sport The Spectator, August 9.

Bergsgard, N.A., Houlihan, B., Mangset, P., Nodland, S.I. \& Rommetvedt, H., 2007. Sport Policy: A comparative analysis of stability and change Oxford: Elsevier.

Bloomfield, J., 2003. Australia's sporting success: the inside story. Sydney: University of New South Wales Press Ltd.

Boyatzis, R., 1998. Transforming qualitative data: Thematic analysis and code development. Thousand Oaks, CA: Sage.

Crabtree, B. \& Miller, W., 1992. A template approach to text analysis: Developing and using codebooks. In B. Crabtree \& W. Miller (eds.) Doing Qualitative Research. Newbury Park: Sage.

Crawford, D., 2009. The future of sport in Australia. Barton.

De Bosscher, V., De Knop, P., Van Bottenburg, M. \& Shibli, S., 2006. A conceptual framework for analysing sports policy factors leading to international success. European Sport Management, 6, 185-215.

De Bosscher, V., Shilbury, D., Theeboom, M., Van Hoecke, J. \& De Knop, P., 2011. Effectiveness of national elite sport policies: A multidimensional approach applied to the case of Flanders. European Sport Management Quarterly, 11, 115141. 
Edwards, A. \& Skinner, J., 2009. Qualitative research in sport management Oxford: Butterworth-Heinemann.

Eisenhardt, K., 1989. Agency Theory: An assessment and review. Academy of Management, 14, 57-74.

Fama, E., 1980. Agency problems and the theory of the firm. Journal of Political Economy, 88, 288-307.

Ferguson, J., 2006. More than sunshine and vegemite: success the Australian way. Broadway: Halstead Press.

Ferkins, L. \& Van Bottenburg, M., 2013. The governance of high performance sport. In K. Sotiriadou \& V. De Bosscher (eds.) Managing High Performance Sport. Milton Park: Routledge, 115 - 135.

Fletcher, D. \& Arnold, R., 2011. A qualitative study of performance leadership and management in elite sport. Journal of Applied Sport Psychology, 23, 223-242.

Fletcher, D. \& Wagstaff, C., 2009. Organisational psychology in elite sport: Its emergence, application and future. Psychology of Sport and Exercise, 10, 427434.

Gall, M., Gall, J. \& Borg, W., 2007. Educational research: an introduction Boston: Pearson.

Gordon, H., 1994. Australia at the Olympic Games St Lucia: University of Queensland Press.

Green, M. \& Collins, S., 2008. Policy, politics and path dependency: sport development in Australia and Finland. Sport Management Review, 11, 225-251.

Green, M. \& Houlihan, B., 2006. Governmentality, Modernisation, and the "Disciplining" of National Sporting Organisations: Athletics in Australia and the UK. Sociology of Sport Journal, 23, 47-71.

Green, M. \& Oakley, B., 2001. Elite sport development systems and playing to win: uniformity and diversity in international approaches. Leisure Studies, 20, 247267.

Grix, J. \& Carmichael, F., 2012. Why do governments invest in elite sport? A polemic. International Journal of Sport Policy and Politics, 4, 73-90.

Grix, J. \& Phillpots, L., 2011. Revisting the 'Governance Narrative': Asymmetrical network governance and the deviant case of the sports policy sector. Public Policy and Administration, 26, 3-19.

Halsey, L., 2009. The true success of nations at recent Olympic Games: comparing actual versus expected medal success. Sport in Society, 12, 1353-1368.

Hendry, J., 2005. Beyond Self-Interest: agency theory and the board in a satisficing world. British Journal of Management, 16, 55-63.

Houlihan, B., 2005. Public sector sport policy: Developing a framework for analysis. International Review for the Sociology of Sport, 40, 163-185.

Houlihan, B., 2013. Commercial, political, social and cultural factors impacting on the management of high performance sport. In P. Sotiriadou \& V. De Bosscher (eds.) Managing High Performance Sport. Milton Park: Routledge.

Houlihan, B. \& Green, M., 2008. Comparative elite sport development Oxford: Elsevier Ltd.

Houlihan, B. \& Zheng, J., 2013. The Olympics and elite sport policy: Where will it all end? The International Journal of the history of sport, 30, 338-355.

Hull, C. 2014. Stop wasting taxpayers money on sport funding The Sydney Morning Herald, February 7. 
Jensen, M. \& Meckling, W., 1976. Theory of the firm: managerial behaviour, agency costs and ownership structure. Journal of financial ecomonics, 3, 305-360.

Kikulis, L., 2000. Continuity and change in governance and decision making in national sport organisations: institutional explanations. Journal of Sport Management, 14, 293-320.

Lane, S. 2012. Coates delivers blunt message to Olympic sport bosses Sydney Morning Herald, August, 13.

Mason, D. \& Slack, T., 2003. Understanding principal-agent relationships: evidence from professional hockey. Journal of Sport Management, 17, 37-61.

Mason, D. \& Slack, T., 2005. Agency theory and the study of sport organisations. Sport in society, 8, 48-64.

Mason, D., Thibault, L. \& Misener, L., 2006. An agency theory perspective on corruption in sport; the case of the International Olympic Committee. Journal of Sport Management, 52-73.

Miles, M. \& Huberman, M., 1984. Qualitative data analysis - a sourcebook of new methods. California: SAGE publications.

Moe, T., 1984. The new economics of organisation. American Journal of Political Science, 28, 739-777.

Oakes, L. 2012. How our pollies can get us to "medal" again NIne Network.

Oakley, B. \& Green, M., 2001. The production of Olympic Champions - International perspectives on elite sport development systems. European Journal for Sport Management, 8, 83-105.

Pratt, J. \& Zeckhauser, R., 1985. Principals and Agents:The structure of business Harvard College: Harvard Business School Press.

Sam, M.P., 2009. The public management of sport. Public Management Review, 11, 499514.

Shapiro, S., 2005. Agency Theory. Annual Review of Sociology, 31, 263-84.

Shilbury, D. \& Kellett, P., 2011. Sport management in Australia Crows Nest: Allen \& Unwin.

Sotiriadou, 2013. The role of High Performance Directors within National SPorting Organisations. In P. Sotiriadou \& V. Debosscher (eds.) Managing High Performance Sport. Oxon: Routledge, 1-13.

Sotiriadou, P., 2009. The Australian sport system and its stakeholders: development of cooperative relationships. Sport in society, 12, 842-860.

Stewart, B., Nicholson, M., Smith, A. \& Westerbeek, H., 2004. Australian Sport: Better by design? The evolution of Australian sport policy. Oxon: Routledge.

Stoddard, B., 2012. Money well spent? The Olympic dash for taxpayers cash [online]. Available from: http://theconversation.com/money-well-spent-the-olympic-dashfor-taxpayers-cash-7618 [Accessed 18 June 2012].

Tasoluk, B., Yaprak, A. \& Calantone, R., 2006. Conflict and collaboration in headquarters-subsidiary relationships. An agency theory perspective on product rollouts in an emerging market. International Journal of Conflict Management, 17, 332-351.

Van Slyke, D., 2006. Agents or stewards: using theory to understand the governmentnonprofit social service contracting relationship. Journal of public administration research and theory, 17, 157-187. 